\title{
Using Respondent-Driven Sampling to Recruit Psychoactive Drug Users: Experiences From a Pilot Study Conducted in Kandy District Sri Lanka
}

\author{
S.D. Nawaratne ${ }^{a, *}$, H.M.J.P. Vidanapathirana ${ }^{\text {b }}$ \\ a Senior Registrar in Community Medicine, Postgraduate Institute of Medicine, University of Colombo, Sri Lanka. \\ ${ }^{b}$ Consultant Community Physician/ Director, National Cancer Control Programme, Ministry of Health, Sri Lanka. \\ *Corresponding author Email: sdnawaratne@gmail.com \\ DOI: https://doi.org/10.54392/ajir2211
}

Received: 30-10-2021; Revised: 02-01-2022; Accepted: 15-01-2022; Published: 04-02-2022

\begin{abstract}
Psychoactive drug users are considered a hidden population and sampling community-based drug users are not feasible with probability sampling methods. The aim of the study was to conduct a pilot study to assess the feasibility of the Respondent Driven Sampling method to sample psychoactive drug users in the community. A community-based pilot study was conducted in Kandy District among 180 psychoactive drug users recruited using Respondent Driven Sampling. Formative assessment was conducted before data collection. Six purposely selected seeds were used. An incentive was provided for every respondent. RDS Analyst free software version 0.64 was used to visualize recruitment trees, recruitment waves, conduct recruitment homophily, convergence analysis, frequency distributions of sociodemographic characteristics and drug use patterns. Seven waves were reached to recruit the 180 drug users in five weeks duration. Two of the six seeds were unproductive. The coupon redeem rate was $34 \%$. Hoping to quit drug use was the main reason for participating in the study. Eighty-one per cent found the data collection site easy or somewhat easy to access. The required sample size was able to achieve with respondentdriven sampling within a short duration of time while fulfilling basic assumptions of respondent-driven sampling. Moreover, the data demonstrate recruiting participants across genders, ethnicities, income levels, occupations, as well as drug use patterns. Therefore, it is a feasible and successful method to recruit psychoactive drug users in the community.
\end{abstract}

Keywords: Psychoactive Drug Users, Pilot Study, Respondent-Driven Sampling.

\section{Introduction}

Psychoactive drug users are considered a hidden population group due to their illegal and stigmatized behaviour (World Health Organization \& United Nations Programme on HIV and AIDS, 2013). In the year 2020, four per cent of the world population had used psychoactive drugs (United Nations Office on Drugs and Crime, 2021). In Sri Lanka, the situation is similar with an estimated half a million drug users ( $3.5 \%$ of the population over 18 years) in 2019 (National Dangerous Drugs Control Board, 2019a). This marginalized group must be researched to develop interventions that will reduce individual and societal harm.

Owing to the lack of a sampling frame, non-probability sampling is the method of choice commonly used to recruit psychoactive drug users. Respondent-driven sampling (RDS) is such sampling method introduced by Douglas Heckathorn, that is used to reach hidden populations for research (Heckathorn, 1997). RDS recruit participants in the population who are linked through social networks similar to snowball sampling but provides estimates with greater mathematical accuracy.

RDS is initiated with purposely selected "seeds" from the targeted population. Recruitment of peers is carried out by handing over coupons. To minimize bias usually associated with such chain referral procedures, in RDS the number of coupons issued are restricted (Gile et al., 2015). In RDS, recruitment expands in waves, and each recruitment is a link in the recruitment chain. Therefore, it allows participants to be traced back to the initial seeds 
(Heckathorn, 2002). Traditionally it also employs a dual system of structured incentives in which participants are compensated for both participating in the study and recruiting their peers (Johnston \& Sabin, 2010).

A chain referral mechanism can introduce an unknown bias into samples with recruitment reflecting affiliation patterns. This is known as homophily. A homophily value greater than one indicates the presence of positive homophily (people recruiting similarly to themselves), while values less than one indicate negative homophily (people are recruiting different from themselves). When network homophily is high, equilibrium takes a long time to reach because recruitment chains have limited mobility across group boundaries. When homophily is moderate or weak, recruitment chains can move more quickly, presumably including the most secluded members of the target population. This reaching of equilibrium can be demonstrated using convergence plots (Gile et al., 2015; Quader et al., 2006).

Respondent-driven sampling is based on several assumptions. These assumptions, in brief, include mutual ties between respondents (e.g. know one another as members of the sampled population); respondents are linked by a single network component; sampling takes place with replacement; respondents can provide accurate network sizes (i.e., number of friends and acquaintances they know from the sampled population); peers are recruited randomly from its network and at least one peer is recruited by each respondent (World Health Organization \& United Nations Programme on HIV and AIDS, 2013).

In Sri Lanka, RDS has been used previously only to recruit key population groups for Integrated Biological and Behavioral Surveillance surveys, conducted by the National STD/AIDS Control Programme, that had focused only on injecting drug users (National STD/AIDS Control Programme, 2015, 2018a). Injecting drug users comprise only a fraction of psychoactive drug users in Sri Lanka. Therefore, despite having a strong theory, there's limited evidence to suggest RDS is a valuable method to reach a diverse group of psychoactive drug users in Sri Lanka.

Our main study was planned for studying a large group of community-based drug users in the Western Province of Sri Lanka. However, embarking on a study with such calibre necessitates meticulous planning. In this regard, conducting a pilot study was important to determine the feasibility of the RDS design to recruit psychoactive drug users and to assess if the RDS process was practical and manageable. Therefore, the current pilot study aimed at assessing the feasibility of using RDS for recruiting psychoactive drug users in the community.

\section{Methods}

The pilot study was conducted in the Kandy District, which has one of the highest numbers of psychoactive drug users in Sri Lanka. According to the National prevalence survey in 2019, an estimated 28,537 drug users reside in this multiethnic district (National Dangerous Drugs Control Board, 2019a).

A person over 18 years, who used psychoactive drugs for non-medical purposes for any duration during the past 12 months preceding the study, in possession of a valid recruitment coupon, and reside or work in the Kandy district at the time of the data collection was taken for the study and those who only use alcohol or tobacco as a psychoactive substance were excluded.

A formative assessment was conducted with the help of psychiatry social workers and non-governmental organizations working with drug users to identify potential "seeds" with large social networks. A Dharmashala (siteI) and two Community Centers (site-II and III) were used to perform the study with good access to public transport facilities. A total of six seeds were selected (five males and one female) who were between 20-45 years of age. A meeting was held for the selected seeds to educate them on the RDS procedure, recruitment criteria, the importance of the current research and the importance of their contribution to improving their community's health and wellbeing. All seeds were informed to pass out three coupons to recruit peers from their networks since three is the most recommended number described in the literature (Gile et al., 2015).

Each site was open two days per week from 9.00am-5.00pm (site-I on Monday and Wednesday; site-II on Tuesday and Thursday; site-III on Friday and Saturday). In the formative assessment, it was decided to assess the time taken to recruit at least one-fifth of the sample of the main study. Therefore, recruitment was continued till 180 drug users were recruited from the Kandy District. Each participant was also issued three coupons that were valid for two weeks. As the recruitment continued to grow it was evident that if the coupon issuing was not controlled 
more than the expected number of drug users will enter the study. Therefore, a decision was taken not to issue new coupons after the sixth wave. This enabled the control of recruitment chain growth and restrict the number of participants entering the study Coupons carried information of the study, site, opened hours and days, contact number and a unique identification number. Each participant was administered a questionnaire by a trained assistant that contained a network question (how many people who use drugs over 18 years they know and know them by name in Kandy District), basic socio-demographic data, drug use pattern within last month, and their experiences of the study process. For every participant was given an incentive as a transportation allowance. No additional allowance was paid for recruiting peers. Each participant was provided with health education materials and those who were willing was referred to the nearest substance use clinic. Since RDS is susceptible to possible re-entry of the same unit (Gile \& Handcock, 2010), For each site, a research assistant was put in place, on all days, to screen the returning coupons for eligibility and to prevent repeat enrolment. Moreover, the same data collectors were present in each site so any repeat entry could be identified.

Tally sheets were maintained to keep track of the coupons issued and returned at each site. Data gathered from each site was first entered into an Excel sheet and then transferred to RDS Analyst free software version 0.64 to visualize recruitment trees and recruitment waves and frequency distribution of socio-demographic factors. The quality of RDS data gathered was assessed using recruitment homophily, convergence analysis. Feasibility was assessed by duration of the study, adequacy of incentive, the ability to reach the sample size as well as the diversity of the sample, and the ability to meet key assumptions in RDS.

\section{Results and Discussion}

A total of five weeks was taken to recruit 180 psychoactive drug users. Out of the six seeds, four were more successful in recruiting peers (Figure 2). The highest number of recruits were recruited through the fifth seed (38.9\%). The number of participants recruited at each wave was demonstrated in Figure 1.

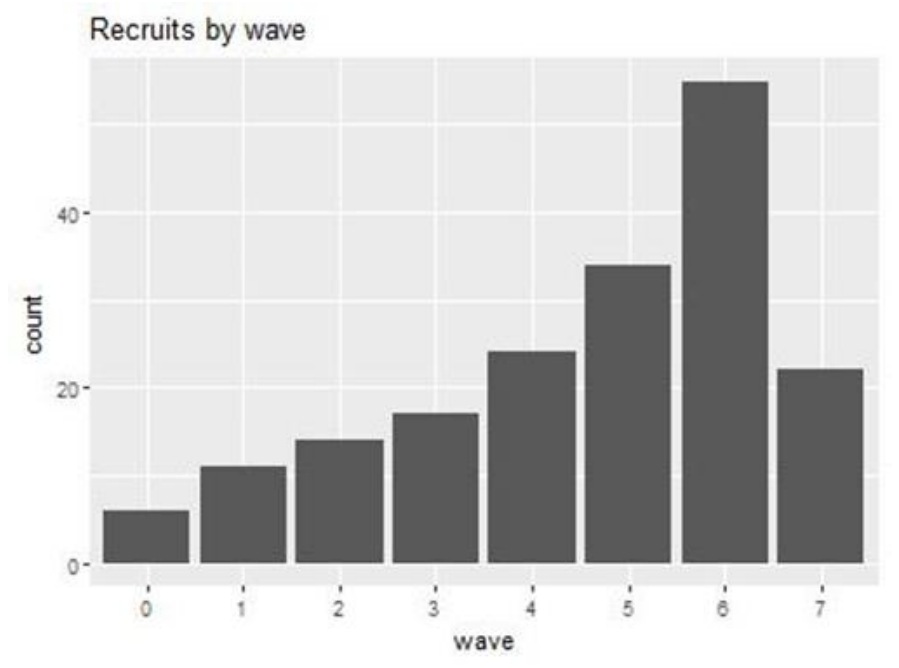

Figure 1. Recruitment of the study participants in the pilot study in each wave.

Even though initially the recruitment was slow, gradually it picked up the pace and achieved the sample faster than expected. McKnight et. al. (2006) explain that this is due to selecting the correct number of seeds. The success of the RDS is understood to be the ability to penetrate the social networks of the hidden populations. Therefore, deciding on the number of coupons and seeds is vital for the continuity of recruitment. By reducing the number of coupons, the recruitment chains can grow longer rather than wider before the sample size is depleted. Furthermore, a small number of seeds can lead to fewer but longer recruitment chains (Johnston et al., 2013). Heckathorn, (1997) describes that after at least six waves, an equilibrium mix of recruits will emerge that is independent of the characteristics of the seeds from which recruitment began. In our study, seven recruitment waves were reached before the completion of recruitment.

On the other hand, increasing the number of coupons and seeds can also shorten the study duration. Shortened recruitment chains significantly reduce the cost of the study. Since one additional day of study will 
generate costs for the research assistants, coordinators, refreshments transportation etc. Therefore, five weeks taken for the current study was satisfactory without exhausting financial resources.

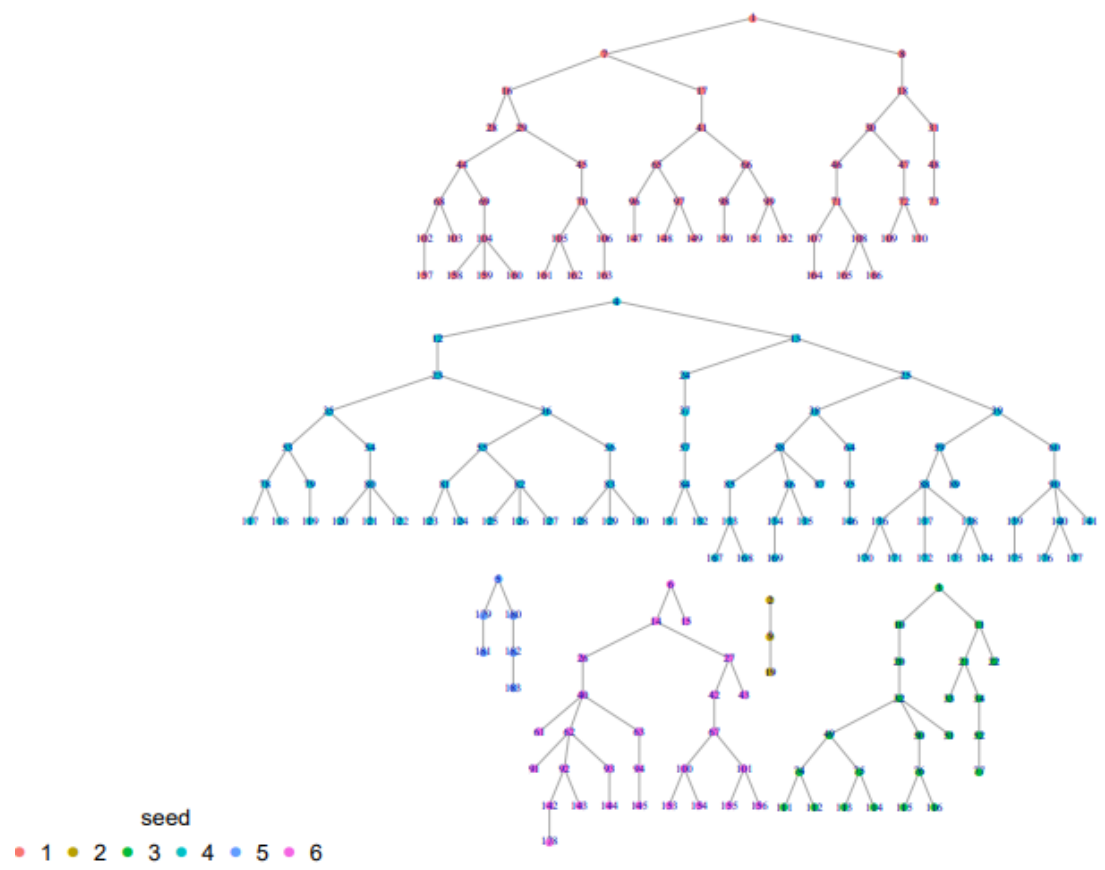

Figure 2. Recruitment trees of participants in the study

For assessing the recruitment homophily several variables were considered (Table 1).

Table 1. Recruitment homophily analysis

\begin{tabular}{|l|l|}
\hline Variable & Recruitment homophily \\
\hline Age & 0.89 \\
\hline Ethnicity & 1.03 \\
\hline Occupation & 0.90 \\
\hline Income & 0.78 \\
\hline Heroin use & 0.94 \\
\hline
\end{tabular}

Overall recruitment homophily ranged from 0.78 to 1.03 . This demonstrated weak homophily in the sample. The presence of weak homophily is suggestive of the removal of seed dependence (Gile \& Handcock, 2010). Moreover, the convergency plots demonstrated reaching of equilibrium around $150^{\text {th }}$ participant (Figure 3 ).

Two out of the six seeds (one male and one female) were not productive (figure 2). Failed seeds are not uncommon in RDS surveys (Johnston et al., 2016). Some surveys replace failed seeds to achieve the desired sample size (Mayo-Wilson et al., 2020). However, in the current study failed seeds were not replaced since the contribution of other seeds were adequate to reach the targeted sample size. Moreover, all participants answered the network question, indicating they were aware of their networks which was a major assumption in RDS methodology.

The coupon redeem rate in the study was 34\% suggesting that at least one peer was recruited by participants which was an assumption in RDS. In the current study, calculating the non-responses was challenging. All those who arrived at the study site completed the interview. But the true non-responses would have been those who refused coupons encountered by the participants in the community. Studies suggest that the non-responses are a combination of coupon refusals and coupon non-returns (Gile et alı, 2015). However, since follow up interview was not conducted, the reasons for coupon refusal could not be elicited, hence the true non-response rate could not be calculated. Despite not all issued coupons being used, the study managed to achieve its desired sample size in a short duration. This could be attributed to the small sample fraction which had allowed participants to be recruited to the study without exhausting the sample population. 
With-replacement sampling is another key assumption in the RDS. However, the current pilot study was conducted strictly without replacement. Though (Gile, 2010) had described that this restriction can lead to inaccurate estimates of sampling probabilities, recent evidence suggests if the population is larger and the sampling fraction is smaller, in practice RDS can be carried out as without replacement sampling. Moreover, during analysis, if used without replacement Successive Sampling (SS) estimator can be used to calculate population parameters as for large
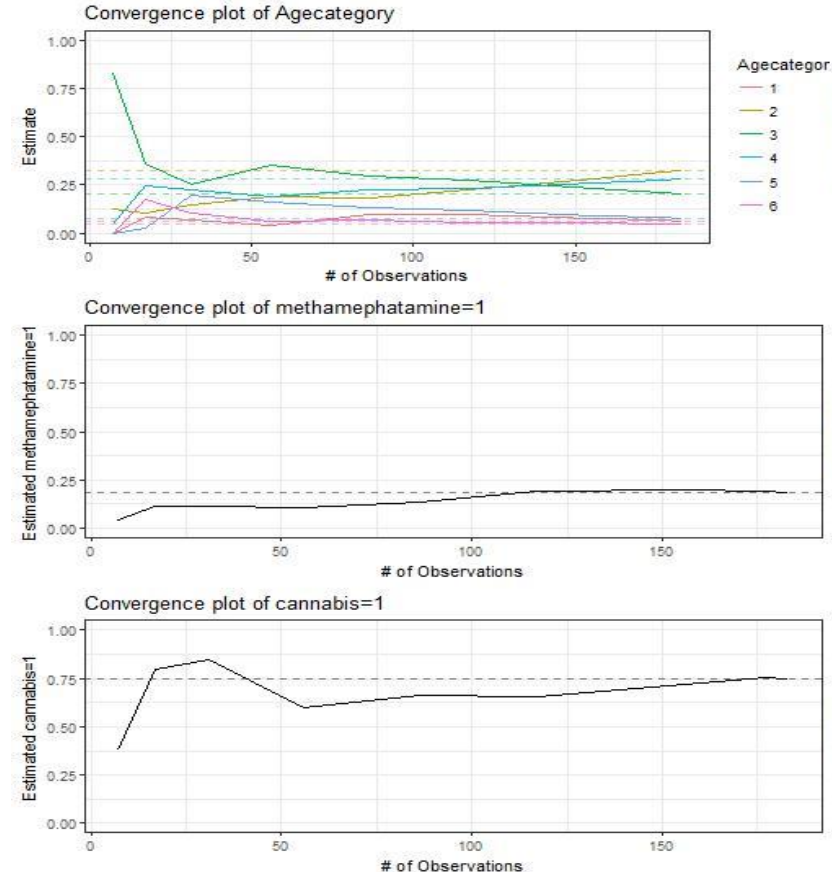

Convergence plot of sex $=1$

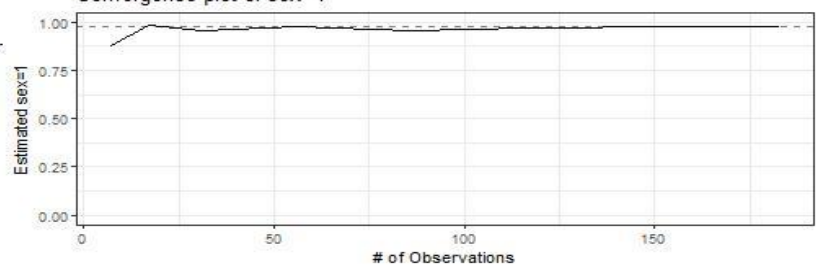

Convergence plot of iv $=1$
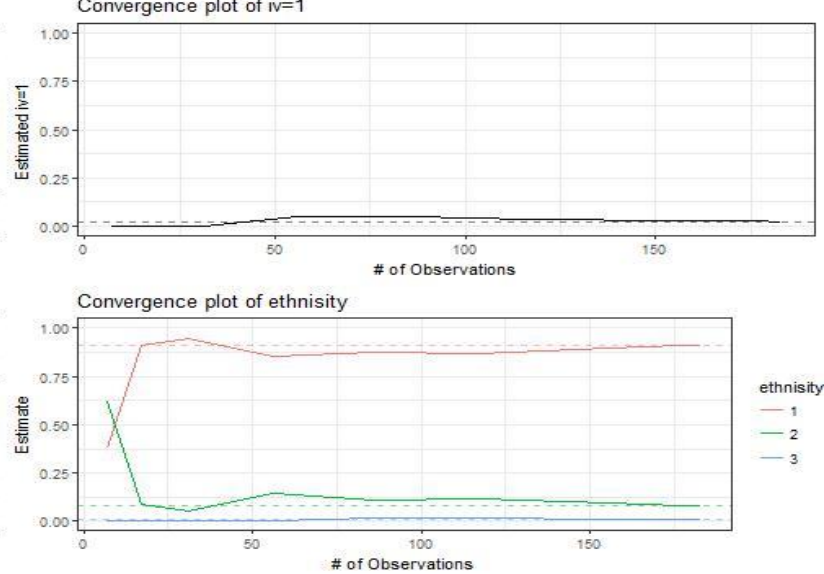

population sizes the SS estimator approaches the traditional Volz-Heckathorn (VH) estimator as the finite population correction is negligible (Spiller et al., 2017).

Figure 3. Convergence plots of the pilot study

Table 2. Socio-demographic characteristic and drug use patterns of the participants

\begin{tabular}{|l|l|l|}
\hline Characteristics & Frequency $\mathbf{( n = 1 8 0 )}$ & Percentage \% \\
\hline Age category & & \\
\hline$<20$ years & 10 & 5.6 \\
\hline $21-30$ years & 36 & 20.0 \\
\hline $31-40$ years & 85 & 47.2 \\
\hline $41-50$ years & 32 & 17.8 \\
\hline $51-60$ years & 12 & 6.7 \\
\hline$>61$ years & 5 & 2.7 \\
\hline Gender & & \\
\hline Female & 2 & 1.1 \\
\hline Male & 178 & 98.9 \\
\hline Ethnicity & & \\
\hline Sinhala & 159 & 88.3 \\
\hline Tamil & 19 & 10.6 \\
\hline Muslim & 2 & 1.1 \\
\hline Occupation & & \\
\hline Unemployed & 18 & 10.0 \\
\hline
\end{tabular}




\begin{tabular}{|c|c|c|}
\hline Managers & 3 & 1.7 \\
\hline Technicians & 5 & 2.8 \\
\hline Clerical support workers & 15 & 8.3 \\
\hline Service and sales workers & 12 & 6.7 \\
\hline Skilled agricultural, forestry and fishery workers & 8 & 4.4 \\
\hline Craft and related trades workers & 4 & 2.2 \\
\hline Plant and machine operators, and assemblers & 4 & 2.2 \\
\hline Elementary occupations & 109 & 60.6 \\
\hline Armed forces occupations & 2 & 1.1 \\
\hline \multicolumn{3}{|l|}{ Monthly income } \\
\hline$<$ Rs. 20,000 & 18 & 10.0 \\
\hline Rs. $20,000-40,000$ & 88 & 48.8 \\
\hline Rs. $41,000-60,000$ & 43 & 23.9 \\
\hline Rs. $61,000-80,000$ & 15 & 8.3 \\
\hline Rs. $81,000-100,000$ & 10 & 5.6 \\
\hline >Rs. 100,000 & 6 & 3.4 \\
\hline \multicolumn{3}{|l|}{ Type of psychoactive drugs used* } \\
\hline Cannabis & 134 & 74.4 \\
\hline Cocaine & 3 & 1.7 \\
\hline Ice & 38 & 21.1 \\
\hline MDMA & 2 & 1.1 \\
\hline Heroin & 95 & 52.8 \\
\hline Tramadol & 42 & 23.3 \\
\hline Diazepam & 26 & 14.4 \\
\hline Pregabalin & 43 & 23.9 \\
\hline Others & 4 & 2.2 \\
\hline \multicolumn{3}{|l|}{ Frequency of drug use } \\
\hline Less than once a month & 7 & 3.9 \\
\hline 1 to 3 times a month & 10 & 5.6 \\
\hline About once a week & 20 & 11.1 \\
\hline 2 to 3 times a week & 17 & 9.4 \\
\hline About once a day & 34 & 18.9 \\
\hline 2 times a day & 33 & 18.3 \\
\hline 3 times a day & 58 & 32.2 \\
\hline More than three times a day & 1 & 0.6 \\
\hline
\end{tabular}

* Multiple responses

The median age of the participants was 38years (ICR \pm 20 years). Only two female drug users (1.1\%) participated in the study and one of the poorly performed seeds was also female. A review of RDS studies conducted in the Eastern Mediterranean Region and the Middle East and North African countries had revealed it is harder to reach women who use drugs than men owing to weaker networking among them (World Health Organization \& United Nations Programme on HIV and AIDS, 2013). Moreover, compared to male drug users female drug users are smaller in number in Sri Lanka (National Dangerous Drugs Control Board, 2019b). This could be the reason for less female participation in the pilot study. The ethnic distribution was representative of the ethnic pattern in Sri Lanka 
(Department of Census and Statistics, 2016). Monthly income and occupation suggested that the majority represent a lower socio-economic group. The drug use pattern of participants in the current study was similar to those of previous studies conducted in Sri Lanka (National STD/AIDS Control Programme, 2018b),

All participants had answered the network size question and it ranged from 15-550. The RDS process evaluation questionnaire results are displayed in table 3.

Table 3. Respondent driven sampling process evaluation questionnaire responses

\begin{tabular}{|c|c|c|}
\hline Question & Frequency & Percentage \% \\
\hline \multicolumn{2}{|l|}{ Reason for participating in the study * } & \\
\hline Incentive given & 64 & 35.6 \\
\hline Wanted to contribute to research benefiting drug users & 57 & 31.7 \\
\hline Hoping to get help to quit use & 109 & 60.6 \\
\hline Curiosity & 31 & 17.2 \\
\hline Other & 12 & 6.7 \\
\hline \multicolumn{3}{|l|}{ Accessing the study site $(n=180)$} \\
\hline Easy & 93 & 51.7 \\
\hline Somewhat easy & 54 & 30.0 \\
\hline Difficult & 26 & 14.4 \\
\hline Other & 7 & 3.9 \\
\hline \multicolumn{3}{|l|}{ Were the given days convenient for you $(n=180)$} \\
\hline Yes & 131 & 72.8 \\
\hline No & 43 & 23.9 \\
\hline Don't know & 6 & 3.3 \\
\hline \multicolumn{3}{|l|}{ Were the opening hours convenient for you $(n=180)$} \\
\hline Yes & 146 & 81.1 \\
\hline No & 24 & 13.3 \\
\hline Don't know & 10 & 5.6 \\
\hline
\end{tabular}

* Multiple responses

Unlike other RDS studies (Johnston et al., 2016), our study only provided an incentive for participation and not for the recruitment of peers. However, participant feedback revealed that compensation was not the primary motivator for taking part but "hoping to get help to quit drug use". Only 35.6\% revealed that incentives motivated them to participate in the study. Therefore, it was evident that the provided incentive was small enough to be noncoercive and adequate.

Several factors may have influenced the finding of the current pilot study. The sites of data collection had good transportation access. Since there was no biological specimen collection, the interview duration was short, and the participants didn't have to spend considerable time at the site. Further, referrals to treatment services for those who sought help was a potential benefit for the participants and a major motivator to get involved and pass the message to their peers. This would have also contributed to the success of recruitment.

\section{Conclusion}


This paper presents evidence from a pilot study to access and sample psychoactive drug users in the community using RDS, which has been shown to reduce several deficiencies associated with the conventional forms of chain referral sampling methods. The study was able to recruit its desired sample size in a short duration of time even after encountering two poorly performing seeds. Moreover, the sample was able to maintain the key functional and analytical assumptions of RDS. The shortened duration of recruitment facilitated in reducing the cost of the study. The recruited sample was diverse in its sociodemographic characteristics (age, ethnicity, occupation, income), and drug use pattern (drug type and drug use frequency), but the sample had similar characteristics of drug users recruited for other drug user's studies conducted among community-based drug users in Sri Lanka. In addition, participants who arrived at the study site completed the study by answering all questions. This demonstrated the acceptability among the participants. Therefore, RDS is a feasible and successful method to recruit psychoactive drug users in the community. Moreover, the practical lessons learnt from the study on seed selection, site selection, study duration, coupon tracking, and incentives will be useful in the successful planning and implementation of a larger study conducted among psychoactive drug users.

\section{References}

Gile, K. J., \& Handcock, M. S., (2010), Respondent-driven sampling: an assessment of current methodology, Social Methodology, 40 (1) 285-327. https://doi.org/10.1111\%2Fj.1467-9531.2010.01223.x

Gile, K. J., Johnston, L. G., \& Salganik, M. J., (2015), Diagnostics for respondent-driven sampling, Journal of the Royal Statistical Society, Series A: Statistics in Society, 178 (1) 241-269. https://doi.org/10.1111/rssa.12059

Heckathorn, D., (1997), Respondent-Driven Sampling: A New Approach to the Study of Hidden Populations, Social Problems, 44 (2) 174-199. https://doi.org/10.2307/3096941

Heckathorn, D., (2002), Respondent-driven sampling II: Deriving valid population estimates from chain-referral samples of hidden populations, Social Problems, 49 (1) 11-34. https://doi.org/10.1525/sp.2002.49.1.11

Johnston, L. G., \& Sabin, K. (2010). Sampling hard-to-reach populations with respondent driven sampling. Methodological innovations online, 5(2), 38-48. https://doi.org/10.4256/mio.2010.0017

Johnston, L. G., Chen, Y.-H., Silva-Santisteban, A., \& Raymond, H. F., (2013), An Empirical Examination of Respondent Driven Sampling Design Effects Among HIV Risk Groups from Studies Conducted Around the World, AIDS and Behavior, 17 (6) 2202-2210. https://doi.org/10.1007/s10461-012-0394-8

Johnston, L. G., Hakim, A. J., Dittrich, S., Burnett, J., Kim, E., \& White, R. G., (2016), A Systematic Review of Published Respondent-Driven Sampling Surveys Collecting Behavioral and Biologic Data, AIDS and Behavior, 20 (8) 1754-1776. https://doi.org/10.1007/s10461-016-1346-5

Mayo-Wilson, L. J., Mathai, M., Yi, G., Mak'anyengo, M. O., Davoust, M., Massaquoi, M. L., Baral, S., Ssewamala, F. M., \& Glass, N. E., (2020), Lessons learned from using respondent-driven sampling (RDS) to assess sexual risk behaviours among Kenyan young adults living in urban slum settlements: A process evaluation, PLoS ONE, 15 (4) 1-22. https://doi.org/10.1371/journal.pone.0231248

McKnight, C., Des Jarlais, D., Bramson, H., Tower, L., Abdul-Quader, A. S., Nemeth, C., \& Heckathorn, D., (2006), Respondent-driven sampling in a study of drug users in New York City: Notes from the field, Journal of Urban Health, 83 (7) 54-59. https://doi.org/10.1007/s11524-006-9102-1

National Dangerous Drugs Control Board (NDDCB)., (2019a), Narcotic and psychoactive drug patterns, Scientific Publications, Colombo, Sri Lanka. http://www.nddcb.gov.lk/Docs/research/Narcotic and Psychotropic.pdf

National Prevalence Survey on Drug Use-2019., (2019b), National Dangerous Drugs Control Board, Colombo, Sri Lanka.

http://www.nddcb.gov.Ik/Docs/research/National\%20Prevalence\%20Survey\%20on\%20Drugs\%20Use\%20 2019.pdf

National STD/AIDS Control Programme (NSACP)., (2015), Integrated Biological and behavioural surveillance (IBBS) survey among Key populations at risk of HIV in Sri Lanka, Colombo, Sri Lanka. Link: https://www.aidscontrol.gov.lk/images/pdfs/publications/research documents/ibbs survey in sri lanka re port print version.pdf

National STD/AIDS Control Programme (NSACP)., (2018), Integrated Biological and Behavioural Surveillance Survey among Key Populations in Sri Lanka, Colombo, Sri Lanka. Link: https://www.aidscontrol.gov.Ik/images/pdfs/publications/research documents/ IBBS-REPORT-PDF.pdf 
National STD/AIDS Control Programme., (2018b), Rapid Assessment of Drug Use Patterns (RADUP), Colombo, Sri Lanka. Link: https://www.aidsdatahub.org/sites/default/files/resource/rapid-assessment-drug-use-patternssri-lanka-2018.pdf

Quader, A. S. A., Heckathorn, D. D., Mcknight, C., Bramson, H., Nemeth, C., Sabin, K., Gallagher, K., \& Jarlais, D. C. Des., (2006), Effectiveness of Respondent-Driven Sampling for Recruiting Drug Users in New York City: Findings from a Pilot Study, Journal of Urban Health, 83 (3) 459-476. https://doi.org/10.1007/s11524-006$\underline{9052-7}$

Spiller, M. W., Gile, K. J., Handcock, M. S., Mar, C. M., \& Wejnert, C., (2017), Evaluating Variance Estimators for Respondent-Driven Sampling, Journal of Survey Statistics and Methodology, 176 (3) 139-148. https://doi.org/10.1093/jssam/smx018

Department of Census and Statistics., (2016), Sri Lanka Demographic and Health Survey (DHS), Colombo, Sri Lanka. Link: http://www.statistics.gov.lk/Health/StaticalInformation/DemographicAndHealthSurvey-2016FullReport

United Nations Office on Drugs and Crime., (2021), World Drug Report 2021: Summary policy implications, Vienna, Austria. Link: https://www.unodc.org/res/wdr2021/field/WDR21 Booklet 1.pdf

World Health Organization \& United Nations Programme on HIV and AIDS, (2013), Introduction to HIV/AIDS and sexually transmitted infection surveillance module 4: Introduction to respondent-driven sampling, World Health Organization, 389.

Funding: No funding was received for conducting this study.

Ethical approval: Ethical approval for the study was obtained from the Ethical Review Committee of Faculty of Medicine, University of Colombo, Sri Lanka (EC-19-055)

Conflict of Interest: The Authors have no conflicts of interest to declare that they are relevant to the content of this article.

\section{About The License}

(C) The Author's 2022. The text of this article is open access and licensed under a Creative Commons Attribution 4.0 International License

\section{Cite this Article}

S.D. Nawaratne and H.M.J.P. Vidanapathirana, Using respondent-driven sampling to recruit psychoactive drug users: experiences from a pilot study conducted in Kandy District Sri Lanka, Asian Journal of Interdisciplinary Research, 5(1) (2022) 1-9. https://doi.org/10.54392/ajii2211 